\title{
Viscoelastic-Plastic-Fracture Modeling of Asphalt Mixtures under Monotonic and Repeated Loads ${ }^{1}$
}

\author{
Yuqing Zhang, Ph.D. \\ Lecturer (Assistant Professor) \\ School of Engineering and Applied Science \\ Aston University \\ MB153A, Aston Triangle, Birmingham, B4 7ET, U.K. \\ Phone: +44 (0) 121-204-3391, Email: y.zhang10@aston.ac.uk \\ (Corresponding Author) \\ Fan Gu, Ph.D. \\ Postdoctoral Researcher \\ National Center for Asphalt Technology (NCAT) \\ 277 Technology Parkway, Auburn, AL 36830 \\ Phone: +1 (334) 844-6251, Email: fzg0014@auburn.edu \\ Bjorn Birgisson, Ph.D., P.E. \\ Distinguished Research Professor and Director \\ Center for Infrastructure Renewal (CIR) \\ Texas A\&M University System \\ 3135 TAMU, CEOB. 201J, College Station, Texas 77843 \\ Phone: +1 (979) 845-6039, Email: bjorn.birgisson@tamu.edu \\ Robert L. Lytton, Ph.D., P.E. \\ Professor, Fred J. Benson Chair \\ Zachry Department of Civil Engineering \\ Texas A\&M University \\ 3136 TAMU, CE/TTI Bldg. 503A, College Station, Texas 77843 \\ Phone: +1 (979) 845-9964, Email: r-lytton@civil.tamu.edu
}

\footnotetext{
${ }^{1}$ This is an Accepted Manuscript of an article published by Transportation Research Record: Journal of the Transportation Research Board.
} 


\begin{abstract}
Rutting and cracking occur simultaneously in asphalt mixtures as observed in the field and laboratory. Existing mechanical models have not properly addressed viscoelastic and viscoplastic deformation together with cracking due to model deficiencies, parameter calibration and numerical inefficiency. This study develops viscoelastic-plastic-fracture (VEPF) models characterizing viscoelasticity (VE) by Prony model and viscoplasticity (VP) by Perzyna's flow rule with a Generalized Drucker-Prager (GD-P) yield surface and a non-associated plastic potential. Viscofracture (VF) damage is modelled by a viscoelastic Griffith criterion and a pseudo J-integral Paris' law for crack initiation and propagation, respectively. The VEPF models are implemented in a finite element (FE) program using a weak form partial differential equation (PDE) modeling technique with no need to program user-defined material subroutines. Model parameters were derived from fundamental material properties using dynamic modulus, strength and repeated load tests. Simulations indicate that the VE-VP-VF characteristics are effectively modelled by the VEPF models for different asphalt mixtures at different confinements and temperatures. An asphalt mixture under monotonic compressive loads exhibits a sequenced process including a pure VE deformation stage, a coupled VE-VP deformation stage, a VE-VP deformation coupled with VF initiation and propagation stage, and then a VE-VF rupture stage with saturated VP deformation. The asphalt mixture under repeated loads yields an increasing VP strain at an increasing rate during the first half of the haversine load while a decreasing VP strain increment with load cycles. The PDE-based FE is capable of effectively modeling the coupled VE-VP-VF behaviors of the asphalt mixtures.
\end{abstract}




\section{INTRODUCTION}

Rutting and cracking in asphalt layers are two primary distresses in flexible pavements. Rutting occurs mainly at high temperatures (e.g., $35^{\circ} \mathrm{C}$ and higher) and cracking occurs at ambient and low temperatures. However, some studies from field/laboratory observations and mechanical analyses indicate that, at high temperatures, cracks grow simultaneously with rutting under external compressive loadings, e.g., surface cracks in the wheel path rutting (1-3), overstress (after peak stress) degradation under a compressive monotonic load $(4,5)$, and the tertiary flow under a compressive repeated load $(6,7)$. Mechanical models such as viscoelastic-plastic continuum damage (VEPCD) models (8-11) and continuum damage mechanics (CDM) models (12-14) have been developed to couple viscoelastic (VE) and viscoplastic (VP) deformation with cracking damage. They have also been implemented in finite element (FE) modeling (e.g., Abaqus) by programming user-defined material subroutines to predict material performance.

However, the coupling of deformation and cracking at a high temperature has not appropriately modelled by the existing models especially under a compressive load. This is due to that 1) yield surface was not used, e.g., VEPCD uses Schapery's VP theory which implicitly assumes that plasticity occurs even at a very tiny load, which is not accurate for asphalt mixtures; or yield surface was used inappropriately, e.g., an asphalt mixture normally has a friction angle larger than $22^{\circ}$, however the CDM models employ the extended Drucker-Prager model which is effectively applicable only for a material with a friction angle less than $\left.22^{\circ}(15) ; 2\right)$ the initiation of damage/cracking was not well defined, e.g., both assume that damage is initiated from the beginning of the load, which may be a reasonable assumption in tension and at low/intermediate temperatures but not in compression or at high temperatures. The cracks don't grow in compression until the material has been hardened due to the accumulation of the VP deformation to a level that a viscoelastic Griffith energy criterion is satisfied (4); and 3) the FE simulations for both models require significant laboratory tests to calibrate model parameters and also need extensive experiences in programming material subroutines. More efforts are also needed to deal with computational problems, i.e., non-convergence, low-efficient iteration, and circular dependency.

This paper aims to remove the above three limitations and model the coupling of the viscoelastic/viscoplastic deformation and cracking for asphalt mixtures under monotonic and repeated loads with a focus on compressive loading and high temperatures. A weak form partial differential equation (PDE) based FE method is used in numerical simulations to free researchers from computer programming and allow one to focus on constitutive modeling of the materials.

\section{CONSTITUTIVE MODELS FOR ASPHALT MIXTURES}

With small deformation and no cracking damage assumed, the total strain of an asphalt mixture subjected to an external load is decomposed into viscoelastic and viscoplastic strains.

$$
\varepsilon_{i j}=\varepsilon_{i j}^{v e}+\varepsilon_{i j}^{v p}
$$

where $\varepsilon_{i j}=$ total strain tensor, $\varepsilon_{i j}^{v e}=$ viscoelastic strain tensor, and $\varepsilon_{i j}^{v p}=$ viscoplastic strain tensor.

\section{Linear Viscoelasticity (VE)}

Under multi-axial stress states, the isotropic constitutive relation for an undamaged linear viscoelastic material is expressed as (16): 
$\sigma_{i j}=\frac{1}{3} \sigma_{k k} \delta_{i j}+s_{i j}=\delta_{i j} \int_{0}^{t} K(t-\tau) \frac{\partial \varepsilon_{k k}^{v e}}{\partial \tau} d \tau+2 \int_{0}^{t} G(t-\tau) \frac{\partial e_{i j}^{v e}}{\partial \tau} d \tau$

where $\sigma_{k k}=\sigma_{11}+\sigma_{22}+\sigma_{33}=$ volumetric stress, $\varepsilon_{k k}^{v e}=\varepsilon_{11}^{v e}+\varepsilon_{22}^{v e}+\varepsilon_{33}^{v e}=$ viscoelastic volumetric strain, $K(t)=$ relaxation bulk modulus, $s_{i j}=\sigma_{i j}-1 / 3 \sigma_{k k} \delta_{i j}=$ deviatoric stress tensor and $\delta_{i j}=$ the Kronecker delta, $e_{i j}^{v e}=\varepsilon_{i j}^{v e}-1 / 3 \varepsilon_{k k}^{v e} \delta_{i j}=$ viscoelastic deviatoric strain, $G(t)=$ relaxation shear modulus, $t=$ a current time of interest, and $\tau=$ an integration variable in time domain. If a solidlike generalized Maxwell (Prony) model is used, the total stress becomes (17):

$\sigma_{i j}=K_{\infty} \varepsilon_{k k}^{v e} \delta_{i j}+2 G_{\infty} e_{i j}^{v e}+\sum_{m=1}^{M}\left[K_{m}\left(\varepsilon_{k k}^{v e}-\varepsilon_{k k}^{m \cdot v i}\right) \delta_{i j}+2 G_{m}\left(e_{i j}^{v e}-e_{i j}^{m \cdot v i}\right)\right]$

where $M=$ total number of the Maxwell elements. $K_{\infty}$ and $G_{\infty}=$ the long term equilibrium bulk modulus and shear modulus, respectively; $K_{m}$ and $G_{m}$ are components of the relaxation bulk and shear moduli, respectively; $\varepsilon_{k k}^{m \cdot v i}$ and $e_{i j}^{m \cdot v i}$ are the viscous bulk and deviatoric strains caused by the $m$-th dashpot $(m=1,2, \ldots, M)$ in the generalized Maxwell model, which are solved by:

$$
\left\{\begin{array}{l}
\left(a_{T} \tau_{m}\right) \dot{\varepsilon}_{k k}^{m \cdot v i}+\varepsilon_{k k}^{m \cdot v i}-\varepsilon_{k k}^{v e}=0 \\
\left(a_{T} \tau_{m}\right) \dot{e}_{i j}^{m \cdot v i}+e_{i j}^{m \cdot v i}-e_{i j}^{v e}=0
\end{array}\right.
$$

where $\tau_{m}=$ relaxation time for the $m$-th dashpot at a reference temperature, and $a_{T}=$ timetemperature shift factor for the modulus, that can be modelled by Arrhenius function as below:

$$
a_{T}(T)=\exp \left[\frac{\Delta E}{R}\left(\frac{1}{T}-\frac{1}{T_{r}}\right)\right]
$$

where $\Delta E$ = activation energy for temperature effect on modulus, $R=$ gas constant, 8.314 $J /(K \cdot m o l) . T=$ temperature of interest, $T_{r}=$ reference temperature.

\section{Viscoplasticity (VP)}

The viscoplastic strain is associated with irrecoverable permanent deformation of the material and its evolution can be defined by a Perzyna-type viscoplasticity theory as (18):

$$
\dot{\varepsilon}_{i j}^{v p}=\Gamma\langle\Phi(f)\rangle^{N} \frac{\partial g}{\partial \sigma_{i j}}
$$

where $\dot{\varepsilon}_{i j}^{v p}=$ rate of the viscoplastic strain with respect to time; $\Gamma=$ a viscosity related parameter. $N=$ a viscoplastic rate dependent exponent. Both $\Gamma$ and $N$ are experimentally determined and $N$ $>1$ for the asphalt mixtures. $f=$ a viscoplastic yield surface function. $g=$ a viscoplastic plastic 
potential function. The non-associated flow rule applies that $g \neq f$, which is appropriate for shearing dilated geo-materials such as asphalt mixtures. The McCauley brackets imply that:

$$
\langle\Phi(f)\rangle=i f[\Phi(f) \leq 0,0, f / 1 P a]
$$

The Perzyna-type model in Eq. 6 has been used to describe asphalt mixture's viscoplastic evolution for decades (19-24). However, most used a yield surface like Mohr-Coulomb, Drucker-Prager (D-P) or extended D-P models which have some significant limitations such as non-smooth or non-convex surfaces when internal frictional angle is greater than $22^{\circ}$. To remove these limitations, the author has developed a generalized Drucker-Prager (GD-P) yield surface model as shown in Equations 8 to $12(15,25)$, allowing a smooth and convex surface for frictional angles varying from zero to $90^{\circ}$.

$$
f=\sqrt{J_{2}} \rho\left(\theta^{\prime}\right)-\alpha I_{1}-\kappa a_{k} a_{\varepsilon}
$$

where $J_{2}=1 / 2 s_{i j} s_{i j}=$ the second invariant of the deviatoric stress tensor; $I_{l}=\sigma_{k k} . \theta^{\prime}=$ the Lode angle that is defined as:

$\theta^{\prime}=\frac{1}{3} \arccos \left[\frac{3 \sqrt{3}}{2} \frac{J_{3}}{\left(J_{2}\right)^{3 / 2}}\right] \quad \in\left[0, \frac{\pi}{3}\right]$

where $J_{3}=\operatorname{det}\left(s_{i j}\right)=$ the third invariant of the deviatoric stress tensor. $\theta^{\prime}=$ zero in compression and $\pi / 3$ in extension. $\rho\left(\theta^{\prime}\right)=$ a function defining the yield surface shape on octahedral plane and determines the convexity of the yield surface, which is expressed as:

$\rho\left(\theta^{\prime}\right)=\mu \cos \left[\frac{1}{3} \arccos \left(\gamma \cos 3 \theta^{\prime}\right)\right]$

where $\mu$ and $\gamma=$ size and shape parameters, respectively, for the yield surface on the octahedral plane to ensure that the yield surface is smooth and convex, which are related to fundamental material properties (e.g., friction angle) by below relations:

$$
\mu=\frac{2 \sqrt{1-d+d^{2}}}{\sqrt{3} d}, \gamma=-\frac{3 \sqrt{3}}{2} \frac{(1-d) d}{\left(1-d+d^{2}\right)^{1.5}}, \quad d=\frac{3-\sin \phi}{3+\sin \phi}
$$

where $d=$ an extension ratio that is the ratio of the yield strength in extension to that in compression. $\phi=$ internal friction angle of the asphalt mixture, which also directly determines the slope of the yield surface on meridian plane by:

$$
\alpha=\frac{2 \sin \phi}{\sqrt{3}(3-\sin \phi)}
$$


The term $\kappa a_{k} a_{\varepsilon}$ in the GD-P model represents the temperature- and rate-dependent cohesion and strain hardening for the asphalt mixture. $\kappa=$ a strain hardening function; $a_{k}$ and $a_{\varepsilon}$ are temperature and strain-rate effect factors, and they are defined as:

$$
\begin{aligned}
& \kappa=\kappa_{0}+\kappa_{1}\left[1-\exp \left(-\kappa_{2} \varepsilon_{e}^{v p}\right)\right] \\
& a_{k}(T)=\exp \left[\frac{\Delta E_{k}}{R}\left(\frac{1}{T}-\frac{1}{T_{r}}\right)\right] \\
& a_{\varepsilon}(\dot{\varepsilon})=a_{\text {min }}+\left(a_{\text {max }}-a_{\text {min }}\right) \exp \left(-\left(\dot{\varepsilon}_{r} / \dot{\varepsilon}\right)^{\kappa_{3}}\right)
\end{aligned}
$$

where $\kappa_{0}$ is a parameter determined by material cohesion $(C)$ and internal friction angle $(\phi)$ :

$$
\kappa_{0}=\frac{6 C \cos \phi}{\sqrt{3}(3-\sin \phi)}
$$

where $\kappa_{1}$ and $\kappa_{2}=$ the material parameters identified at the reference temperature $\left(T_{r}\right)$ and a reference strain-rate $\left(\dot{\varepsilon}_{r}\right)$. They determine the size and shape of the strain hardening yield surface, respectively. $\Delta E_{k}=$ the activation energy for the temperature effect on cohesion, $\dot{\varepsilon}=\mathrm{a}$ strain rate of interest, and $\kappa_{3}=$ a material property accounting for the effect of strain-rate on cohesion. $a_{\min }$ and $a_{\max }$ are theoretical minimum and maximum strain-rate effect factors. $\varepsilon e^{v p}=$ an effective viscoplastic strain under multi-axle stress loadings, that is derived as (25):

$$
\dot{\varepsilon}_{e}^{v p}=\left[\left(\frac{1-\sqrt{3} \beta}{1-\sqrt{3} \alpha}\right)^{2}+2\left(\frac{0.5+\sqrt{3} \beta}{1-\sqrt{3} \alpha}\right)^{2}\right]^{-\frac{1}{2}} \sqrt{\dot{\varepsilon}_{i j}^{v p} \dot{\varepsilon}_{i j}^{v p}}
$$

where $\beta=$ the slope of the viscoplastic potential surface. Integrating Eq. 17 over time gives the effective viscoplastic strain. The viscoplastic potential function $(g)$ determines the direction of the viscoplastic strain increment. It is assumed that the viscoplastic potential surface has the same linear form as the yield surface but with a smaller slope which affects the volumetric dilation of the material:

$g=\sqrt{J_{2}} \rho\left(\theta^{\prime}\right)-\beta I_{1}$

A number of studies have indicated that $\beta<\alpha$ is valid for geo-materials such as soils, sands, and asphalt mixtures $(22,26) . \beta$ is derived to be a function of anisotropy:

$\beta=0.5889 \Delta^{\prime}-0.0122$

where $\Delta^{\prime}=$ modified vector magnitude for microstructural anisotropy of the asphalt mixture that has a value from 0.2 to 0.5 and can be experimentally determined (27). 


\section{Viscofracture (VF)}

Once a material is damaged, the load applied on the material is transferred or carried out by the remaining undamaged (effective or intact) material. It is argued that an effective stress acting on the intact material drives the viscoelastic and viscoplastic deformation $(28,29)$. Thus the aforementioned VE and VP constitutive equations are valid only in the effective (undamaged) configuration and the stresses $\left(\sigma_{i j}\right)$ used in these models should be the effective stresses. However, the stresses measured on the damaged/cracked material in the laboratory or field are apparent stresses $\left(\sigma_{i j}^{A}\right)$ that are affected by cracking damage, and the apparent modulus also degrades with crack evolution. Thus the effective stresses need to be related to the apparent stresses by the damage characteristics. Based on continuum damage mechanics (CDM) $(28,30)$, a damage density is defined as below to capture the overall fracture properties and relate the apparent responses to the effective responses and material properties.

$$
\xi=A^{c} / A^{T}
$$

where, $\xi=$ damage density, $A^{c}=$ lost area due to damages such as voids, flaws and cracks and $A^{T}$ $=$ total cross-sectional area of the material. According to the CDM theories, two equilibrium principles (i.e., force and energy) and isotropic damage are hypothesized between the undamaged (effective) configuration and the damaged (apparent) configuration, leading to:

$$
\sigma_{i j}^{A}=\sigma_{i j}(1-\xi)
$$

$\varepsilon_{i j}=\varepsilon_{i j}^{A}(1-\xi)$

where $\sigma_{i j}$ and $\varepsilon_{i j}=$ effective stress and strain defined in the effective configuration; $\sigma^{A} i j$ and $\varepsilon^{A} i j=$ apparent stress and strain defined in the apparent configuration and measured in the laboratory.

The crack (damage) initiation criterion is proposed by the authors (4) and defined by the viscoelastic Griffith theory, i.e., cracks will grow when the below energy equation is satisfied:

$$
R P S E-\frac{1}{2} D P S E=\frac{7}{6} \pi \frac{\Delta G}{c}
$$

where $R P S E=\left(\sigma_{11}{ }^{2}+\sigma_{22}{ }^{2}+\sigma_{33^{2}}{ }^{2} /\left(2 E_{R}\right)+2\left(1+v_{R}\right)\left(\sigma_{12}{ }^{2}+\sigma_{23}{ }^{2}+\sigma_{13^{2}}{ }^{2} / E_{R}=\right.\right.$ recoverable pseudostrain energy (density), $E_{R}$, and $v_{R}=$ reference modulus and Poisson's ratio which are derived to be Young's modulus and elastic Poisson's ratio (31). DPSE = dissipated pseudo-strain energy (density) due to the accumulation of the viscoplastic deformation, and DPSE $=\int_{0}^{t} \sigma_{i j} \dot{\varepsilon}_{i j}^{v p} d t . c=$ average air void radius that is also the critical crack size at which crack starts to grow. Based on the work by Zhang et al., $c$ can be calculated by Equation 24 with $\mathrm{R}^{2}=0.7431$ (4):

$$
c=0.0037(\% A V)^{2}+0.0071(\% A V)+0.5583
$$

where $\% A V=$ air void content of asphalt mixture in percentage. $\Delta G=$ bond energy of the asphalt mixture, which represents a combined bond energy for cohesive fracture and adhesive fracture. A higher temperature or a lower loading rate induces more percentage of cohesive fracture and 
therefore leads to a lower bond energy (4). The temperature and rate dependent bond energy for an asphalt mixture is modelled as:

$$
\begin{aligned}
& \Delta G(T)=a_{G}(T) a_{\varepsilon}(\dot{\varepsilon}) \Delta G\left(T_{r}\right) \\
& a_{G}(T)=\exp \left[\frac{\Delta E_{G}}{R}\left(\frac{1}{T}-\frac{1}{T_{r}}\right)\right] \\
& a_{\varepsilon}(\dot{\varepsilon})=E q .15
\end{aligned}
$$

where $a_{G}=$ temperature shift factor for bond energy; $\Delta E_{G}=$ activation energy for temperature effect on bond energy. $a_{\varepsilon}=$ a factor accounting for the strain rate effect on the bond energy which is assumed to have the same formulation as the strain rate effect factor on the material cohesion. The crack damage evolution in below was developed based on a pseudo J-integral Paris' law (5). Note the pseudo J-integral Paris' law has been successfully used to model fatigue cracking of asphalt mixtures $(32,33)$ as well as the fracture properties of field-aged mixtures (34) and warm mix (35):

$$
\frac{d \xi}{d t}=A\left(\Delta J_{R}\right)^{n}=A\left[\frac{H}{2} \frac{(3+\xi)}{(1-\xi)^{3}} R P S E\right]^{n}
$$

where $\dot{\xi}=$ rate of damage density; $A$ and $n=$ Paris' law coefficients that are demonstrated to be independent of loading mode, rate, and temperature (5); $\Delta J_{R}=$ pseudo J-integral per loading step; $H=$ height of a laboratory sample or thickness of an asphalt layer in the pavement. It's noted that Eq. 23 and Eq. 28 are for crack initiation and propagation modeling of asphalt mixture in compression. Similar models based on the same principles (i.e., viscoelastic Griffith criterion and pseudo J-integral Paris law) have been derived for those in tension which will be employed in the future studies.

\section{A Viscoelastic-Plastic-Fracture (VEPF) Constitutive Model}

An apparent (damaged) constitutive relation is formulated between apparent stress and apparent strain by substituting Eqs. 1, 21 and 22 into Eq. 3:

$$
\begin{aligned}
\sigma_{i j}^{A} & =(1-\xi)^{2}\left[K_{\infty}\left(\varepsilon_{k k}^{A}-\varepsilon_{k k}^{v p A}\right) \delta_{i j}+2 G_{\infty}\left(e_{i j}^{A}-e_{i j}^{v p A}\right)\right] \\
& +(1-\xi) \sum_{m=1}^{M}\left\{K_{m}\left[\left(\varepsilon_{k k}^{A}-\varepsilon_{k k}^{v p A}\right)(1-\xi)-\varepsilon_{k k}^{m \cdot v i}\right] \delta_{i j}+2 G_{m}\left[\left(e_{i j}^{A}-e_{i j}^{v p A}\right)(1-\xi)-e_{i j}^{m \cdot v i}\right]\right\}
\end{aligned}
$$

where $\xi=$ damage density by integrating Eq. 28 over time. $\varepsilon_{k k}^{A}$ and $e_{i j}^{A}$ are bulk and deviatoric components of apparent total strain $\varepsilon_{i j}^{A}$ that is determined as $\varepsilon_{i j}^{A}=\left(u_{i, j}+u_{j, i}\right) / 2 \cdot \varepsilon_{k k}^{v p A}$ and $e_{i j}^{v p A}$ are bulk and deviatoric components of apparent viscoplastic strain $\varepsilon_{i j}^{v p A}$ that is defined as 
$\varepsilon_{i j}^{v p A}=\varepsilon_{i j}^{v p} /(1-\xi)$, and $\varepsilon_{i j}^{v p}$ is an integration of Eq. 6 over time. $\varepsilon_{k k}^{m \cdot v i}$ and $e_{i j}^{m \cdot v i}$ are bulk and deviatoric components of the effective (undamaged) viscous strain caused by the $m$-th dashpot and they are solved using Eq.4 by setting $\varepsilon_{k k}^{v e}=\left(\varepsilon_{k k}^{A}-\varepsilon_{k k}^{v p A}\right)(1-\xi)$ and $e_{i j}^{v e}=\left(e_{i j}^{A}-e_{i j}^{v p A}\right)(1-\xi)$.

\section{NUMERICAL IMPLEMENTATION}

The viscoelastic constitutive equations (Eqs. 2, 3, and 4) have been successfully implemented in a weak form partial differential equation (PDE) based finite element (FE) modeling program, Comsol Multiphysics, and it demonstrates that accurate viscoelastic responses can be predicted. Moreover, unlike Abaqus, no material subroutine is needed for modelling user-defined constitutive relations (17). Following this work, the viscoplastic and viscofracture constitutive models are converted to Weak Expressions and coupled with viscoelastic PDE models and solved simultaneously using weak form PDE modeling. The key simulation steps are described as below. (A bold and italic expression represents a module or a defined variable in the Comsol program).

(1) Define material properties in Parameters and Variables as model inputs. The Parameters are summarized in Table 1. The Variables include $a_{T}$ (Eq.5), $f$ (Eq.8), $\kappa$ (Eq.13), $a_{k}$ (Eq.14), $a_{\varepsilon}$ (Eq.15), $A_{e}$ (Eq.17), $g$ (Eq.18), $a_{G}$ (Eq.26) and $a_{\varepsilon}$ (Eq.27) which are functions of the Parameters.

(2) Define Dependent Variables (DVs) in four separate Weak Form PDE modules.

- VE: viscous volumetric strains ( $\varepsilon_{k k}^{m \cdot v i}$ in Eq. 4a) defined as $\boldsymbol{u 1 m}$, where $m=1,2, \ldots, M$.

- VE: viscous deviatoric strains ( $e_{i j}^{m \cdot v i}$ in Eq. $\left.4 \mathrm{~b}\right)$ defined as $\mathbf{u} 2 \boldsymbol{m}_{i j}, i j=11,12,23,22,23$, 33.

- VP: viscoplastic strains ( $\varepsilon_{i j}^{v p}$ in Eq. 6) defined as $\boldsymbol{u} 3_{i j}$, where $i j=11,12,23,22,23,33$.

- VF: damage density ( $\xi$ in Eq. 28 ) that is expressed as $\mathbf{u} 4$ in the program.

In addition, global DVs have been defined in the Linear Elastic Material module that include displacement components in three directions, i.e., $u, v$, and $w$.

(3) Convert VE, VP, and VF constitutive equations into Weak Expressions as below. Comsol will perform a numerical integration of the Weak Expressions over a volumetric region (e.g., the FE model of a sample or a structure) and find the solutions for all DVs.

- VE volumetric constitutive equation Eq. 4(a) is converted to: $-\left(a_{T} * \tau_{m} * d(u 1 m, T I M E)+(u 1 m)-\right.$ solid.eelvol $\left.*(1-u 4)\right) *$ test $(u 1 m)$

- VE deviatoric constitutive equation Eq. 4(b) is converted to: $-\left(a_{T} * \tau_{m} * d\left(u 2 m_{i j}, T I M E\right)+\left(u 2 m_{i j}\right)-\right.$ solid.eeldev $\left._{i j} *(1-u 4)\right) *$ test $\left(u 2 m_{i j}\right)$

- VP initiation and evolution Eqs. 6 and 7 for viscoplastic strain are converted to: $-\left(d\left(u 3_{i j}, T I M E\right)-\Gamma *(\text { if }(f \leq 0,0, f / 1 P a))^{N} * d\left(g\right.\right.$, solid.Sl $\left.\left.l_{i j}\right)\right) * \operatorname{test}\left(u 3_{i j}\right)$

- VF initiation and evolution Eqs. 23 and 28 for viscofracture damage are converted to: $-\left(d(u 4, T I M E)-i f\left(R P S E-\frac{1}{2} D P S E<\frac{7}{6} \pi \frac{\Delta G}{c}, 0, A^{*}\left(\frac{H}{2} \frac{3+u 4}{(1-u 4)^{3}} R P S E\right)^{n}\right)\right) * \operatorname{test}(u 4)$ 
(4) Update apparent stress using Eq. 29, which is presented as:

$$
\begin{aligned}
& \text { Solid.Sl } l_{i j}=(1-u 4)^{2} *\left[K_{\infty}(\text { solid.eelvol })+2 G_{\infty}\left(\text { solid.eelde }_{i j}\right)\right]+(1-u 4) *
\end{aligned}
$$

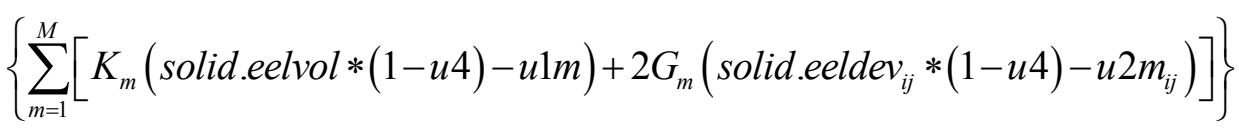

where $\boldsymbol{d}(\boldsymbol{u}, \mathbf{T I M E})$ is a time derivative of a variable $u$. solid.eelvol and solid.eeldev $_{i j}$ are volumetric and deviatoric components of apparent viscoelastic strains (solid.eel $\boldsymbol{i}_{i j}$ ) which are determined in the Linear Elastic Solid module and solid.eel $\boldsymbol{~}_{i j}=$ solid.el $_{i j}-\mathbf{u} \mathbf{3}_{i j}$. Note that solid.el $\mathbf{~}_{i j}$ is apparent total strain and $\boldsymbol{u} \mathbf{3}_{i j}$ is apparent viscoplastic strain since the apparent stress solid.S $\boldsymbol{I}_{i j}$ is used in Eq. 29. $\operatorname{test}(\boldsymbol{u})$ is a test function operating on the dependent variable $\boldsymbol{u}$. Note that the weak form of a PDE is a generalization of the Virtual Work Principle and the test $(u)$ is equivalent to virtual displacement and $\boldsymbol{u}$ is regarded as an internal state variable. One can find that it is very efficient and no user-coded subroutine is needed to convert the mathematical constitutive equations to weak expressions which can be directly implemented in the PDE-FE modeling to perform numerical simulations.

\section{MATERIAL PROPERTIES AS MODEL INPUTS}

Model input parameters are critically important for accurate FE predictions of material behaviors. An existing method for model calibration, i.e., determination of model parameters, is performed via fitting the FE predictions to a series of test results and minimizing the overall errors between test results and the FE predictions by adjusting the model parameters $(13,36)$. An argument is that the nonlinear regression can lead to non-unique solutions to the model parameters and eventually cause incorrect predictions of the material behaviors when the models are used in a condition that is not included in the model parameter calibration. Instead the authors identify the model parameters from the fundamental material properties and mechanical relationships. A number of unique relationships have been derived between the model parameters and material properties (e.g., Eqs. 11, 12, 16, 19, and 24). The authors have also presented systematic testing and data analysis methods in previous studies to determine the material properties and model parameters, details of which are not repeated in this paper but referred to the publications $(4,5,17,25,37)$.

Four asphalt mixtures were selected to validate the VEPF models and the weak form PDE based FE modeling. Table 1 summarizes the four mixtures, test methods, testing parameters, material properties and the corresponding references where the data were reported. For VE characterization, dynamic modulus master curves were constructed to determine the Prony model parameters of the relaxation bulk and shear moduli, as well as the modulus time-temperature shift factor (17). Lateral surface scanning tests were used to determine the anisotropic vector magnitude $\left(\Delta^{\prime}\right)$ so that the slope of the plastic potential $(\beta)$ can be calculated (25). The VP yield surface and strain hardening parameters were determined from the constant-strain-rate compressive strength (CS) tests (using the stress-strain curve before peak stress) at different confinements and temperatures (37). The Perzyna's parameters were determined by destructive repeated load (RL) tests to evaluate the viscosity and loading rate dependence (25). The bond energy $(\Delta G)$ can be back-calculated from compressive strength based on the CS test or estimated by cohesive and adhesive surface energy components measured by surface chemistry tests (4). The Paris' law coefficients for VF models were proven to be independent of temperature, 
loading mode and rate, which were identified by the overstress part (after the peak stress) of the CS tests (5) or the tertiary flow part of the RL tests (6). Note that pseudo-strain was used to perform strain decomposition in all destructive tests (CS and RL) so that the total strain is decomposed into VE, VP, and VF strains which are used individually to determine the corresponding material properties.

\section{RESULTS AND DISCUSSIONS}

Figure 1 compares the stress-strain curves of the compressive strength test and the FE modeling. One can find that VE models (in section 2.1) can only predict the material responses before the initial yield stress (point $A$ ), which is an undamaged and pure viscoelastic process. The VP strain start to accumulate from point $A$ as shown in Fig.1. VEP models including VE and VP constitutions (in sections 2.1 and 2.2) can predict the material responses until the peak stress (point $C$ ), after which the VEP prediction shows a perfect-plastic behavior (a flat stress-strain curve) which is unreasonable for the mixture. It is also found that the VEP predictions match with the test data in part $A B$, whereas mismatch in part $B C$. Point $B$ is the moment when the cracking damage is initiated and the damage density begins to grow (see Fig.1). Thus VEP predicting errors in part $B C$ result from the cracking damage. The VEPF model consisting of VE, VP, and VF constitutions accurately predicts the whole stress-strain curve, which demonstrates that it can model the coupling of the VE, VP and VF characteristics of the material. Note that the peak stress corresponds to a damage density of $4 \%$ which equals the air void content of the sample. The same results were found for all tested and modelled samples. This is reasonable since the air void radius was used in Eq.24 to estimate the critical crack size that defines the crack initiation by Eq. 23. Thus it is believed that the part $B C$ is a stage coupled VE-VP-VF process with crack initiation and, after the peak stress, part $C D$ is a stage coupled VE-VP-VF process with an increasing VP strain and growing VF damage density, i.e., crack propagation. Fig. 1 also shows that VP strain becomes saturated at point $D$, after which the material is in a VEVF rupture process.

Figs. 2, 3, and 4 shows the stress-strain curves of the compressive strength test and VEPF modeling results for the four different asphalt mixtures at one temperature without confinement, one mixture (N4-0) at three confining pressures, and one mixture (N4-6) at five temperatures, respectively. It is concluded from the fairly good match between FE modeling and the test results that the VEPF model can accurately characterize the coupling of the VE, VP and VF material responses for different asphalt mixtures and at different confinements and temperatures.

Further VEPF modeling was performed on the asphalt mixture under haversine repeated and cyclic loads. As shown in Figures 5 and 6, the load amplitude was $1 \mathrm{MPa}$ and loading period was $40 \mathrm{sec}$, where the repeated load has no rest period and the cyclic load has a rest period of 40 sec. Three cycles were modelled using VEPF models in Comsol. It can be found that the total strain, VE strain and VP strain are predicted by the models, where the total and VE strain lag behind the stress due to viscoelastic relaxation. The VE strain dominates the total strain. The VP strain starts to grow after a period of time in the first half of each haversine load cycle rather than from the very beginning of the cycle as indicated in the existing modeling. This demonstrates that the yield surface has to be achieved before the VP strain accumulates. The increase of the VP strain in each load cycle exhibits an increasing slope which differs from the decreasing slope as reported in the literature. The increasing rate of the VP strain results from the increasing deriving forces $\left(\sqrt{J_{2}} \rho\left(\theta^{\prime}\right)-\alpha I_{1}\right)$ due to the increasing external load and the declining hardening resistance $\left(\kappa a_{k} a_{\varepsilon}\right)$ due to the decreasing total strain rate, which is true for the first half of the 
haversine loading. Figures 5 and 6 also show that the total VP strain increment in a load cycle is less than that in the previous load cycle. This is caused by the viscoelastic strain hardening resulting from the VP strain accumulation with the repeated load cycles. Comparing Figure 5 to Figure 6 shows that the rest period does not affect the accumulation of the VP strain, however it must be noted that the viscofracture has not been introduced since only three cycles were simulated in this study. Coupling VF with VP under repeated/cyclic loads considering loading rate dependence as well as their predictions comparing with laboratory test results will be continuing studies after this paper.

\section{CONCLUSIONS}

The study developed a coupled viscoelastic-plastic-fracture (VEPF) constitutive models for asphalt mixtures. The viscoelasticity (VE), viscoplasticity (VP) and viscofracture (VF) material behaviors of asphalt mixtures were simulated under monotonic and repeated loading conditions using a weak form partial differential equation (PDE) based finite element modeling (FEM) technique with no need of programming a material subroutine. The below conclusions were drawn from the study.

- Viscoelastic and viscoplastic deformation occur simultaneously with viscofracture damage for asphalt mixtures in compression and at high temperatures. The developed VEPF model can model the initiation and evolution of both viscoplastic deformation and viscofracture cracking for different mixtures and at varying confinements and temperatures.

- Under a monotonic compressive load, the asphalt mixtures exhibit a sequenced process including a pure VE stage before initial yielding, a VE/VP strain accumulation stage, a $\mathrm{VE} / \mathrm{VP} / \mathrm{VF}$ crack initiation stage before peak stress, a VE/VP/VF crack propagation stage until a final rupture stage that is a VE/VF stage with a saturated VP deformation.

- Under a repeated/cyclic load, the VE strain lags behind the stress and the VP strain increases following an increasing rate after the yielding criteria is achieved during the first half of the loading period. The total VP strain increment in a load cycle declines with load cycles due to strain hardening effect.

- Weak form PDE based FE method can effectively compute the complex VE/VP/VF constitutive models and predict the material behaviors for asphalt mixtures without a need of programming material subroutines. The models have been validated with monotonic loading tests and more validations of the VEPF models in PDE-FE modeling are being performed for asphalt mixtures under repeated loads and in tensile conditions.

\section{REFERENCES}

1. Wang, L.B., L.A. Myers, L.N. Mohammad, and Y.R. Fu. Micromechanics Study on TopDown Cracking. In Transportation Research Record: Journal of the Transportation Research Board, No. 1853, Transportation Research Board of the National Academies, Washington, D.C., 2003, pp. 121-133.

2. Freitas, E.F., P. Pereira, L. Picado-Santos, and A.T. Papagiannakis. Effect of Construction Quality, Temperature, and Rutting on Initiation of Top-Down Cracking. In Transportation Research Record: Journal of the Transportation Research Board, No. 1929, Transportation Research Board of the National Academies, Washington, D.C., 2005, pp. 174-182. 
3. Underwood, B., T. Yun, and Y. Kim. Experimental Investigations of the Viscoelastic and Damage Behaviors of Hot-Mix Asphalt in Compression. Journal of Materials in Civil Engineering, Vol. 23, No. 4, 2011, pp. 459-466.

4. Zhang, Y., X. Luo, R. Luo, and R.L. Lytton. Crack Initiation in Asphalt Mixtures under External Compressive Loads. Construction and Building Materials, Vol. 72, No. 2014, pp. 94-103.

5. Zhang, Y., B. Birgisson, F. Gu, and R.L. Lytton. Crack Evolution of Asphalt Mixtures under Compressive Monotonic and Repeated Loads. In The 8th Rilem International Conference on Mechanisms of Cracking and Debonding in Pavements (MCD2016), Springer, Nantes, France, 2016.

6. Zhang, Y., R. Luo, and R.L. Lytton. Mechanistic Modeling of Fracture in Asphalt Mixtures under Compressive Loading. Journal of Materials in Civil Engineering, Vol. 25, No. 9 , 2013, pp. 1189-1197.

7. Zhang, Y., R. Luo, and R.L. Lytton. Anisotropic Characterization of Crack Growth in Tertiary Flow of Asphalt Mixtures in Compression. Journal of Engineering Mechanics, Vol. 140, No. 6, 2014, pp. 04014032.

8. Schapery, R.A. A Theory of Mechanical Behavior of Elastic Media with Growing Damage and Other Changes in Structure. Journal of the Mechanics and Physics of Solids, Vol. 38, No. 2, 1990, pp. 215-253.

9. Chehab, G.R., Y.R. Kim, R.A. Schapery, M.W. Witczak, and R. Bonquist. Characterization of Asphalt Concrete in Uniaxial Tension Using a Viscoelastoplastic Continuum Damage Model. Journal of the Association of Asphalt Paving Technologists, Vol. 72, No. 2003, pp. 315-355.

10. Underwood, S. and R. Kim. Viscoelastoplastic Continuum Damage Model for Asphalt Concrete in Tension. Journal of Engineering Mechanics, Vol. 137, No. 11, 2011, pp. 732739.

11. Uzan, J. Viscoelastic-Viscoplastic Model with Damage for Asphalt Concrete. Journal of Materials in Civil Engineering, Vol. 17, No. 5, 2005, pp. 528-534.

12. Darabi, M.K., R.K. Abu Al-Rub, E.A. Masad, C.-W. Huang, and D.N. Little. A ThermoViscoelastic-Viscoplastic-Viscodamage Constitutive Model for Asphaltic Materials. International Journal of Solids and Structures, Vol. 48, No. 1, 2011, pp. 191-207.

13. Abu Al-Rub, R.K., M.K. Darabi, C.-W. Huang, E.A. Masad, and D.N. Little. Comparing Finite Element and Constitutive Modeling Techniques for Predicting Rutting of Asphalt Pavements. International Journal of Pavement Engineering, Vol. 13, No. 4, 2012, pp. 322 338.

14. Huang, C.W., R.K. Abu Al-Rub, E.A. Masad, and D.N. Little. Three-Dimensional Simulations of Asphalt Pavement Permanent Deformation Using a Nonlinear Viscoelastic and Viscoplastic Model. Journal of Materials in Civil Engineering, Vol. 23, No. 1, 2011, pp. 56-68.

15. Zhang, Y., M. Bernhardt, G. Biscontin, R. Luo, and R. Lytton. A Generalized DruckerPrager Viscoplastic Yield Surface Model for Asphalt Concrete. Materials and Structures, Vol. 48, No. 11, 2014, pp. 3585-3601.

16. Findley, W.N., J.S. Lai, and K. Onaran, Creep and Relaxation of Nonlinear Viscoelastic Materials with an Introduction to Linear Viscoelasticity. Dover Publication, Inc., Mineola, New York, 1989. 
17. Zhang, Y., B. Birgisson, and R.L. Lytton. Weak Form Equation-Based Finite-Element Modeling of Viscoelastic Asphalt Mixtures. Journal of Materials in Civil Engineering, Vol. No. 2015, pp. 04015115.

18. Perzyna, P. Thermodynamic Theory of Viscoplastcity. Advances in Applied Mechanics, Vol. 11, 1971, pp. 313-354.

19. Abdulshafi, A. and K. Majidzadeh. Combo Viscoelastic-Pastic Modeling and Rutting of Asphalt Mixtures. In Transportation Research Record: Journal of the Transportation Research Board, No. 968, Transportation Research Board of the National Academies, Washington, D.C., 1984, pp. 19-31.

20. Seibi, A., M. Sharma, G. Ali, and W. Kenis. Constitutive Relations for Asphalt Concrete under High Rates of Loading. In Transportation Research Record: Journal of the Transportation Research Board, No. 1767, Transportation Research Board of the National Academies, Washington, D.C., 2001, pp. 111-119.

21. Masad, E., S. Dessouky, and D. Little. Development of an Elastoviscoplastic Microstructural-Based Continuum Model to Predict Permanent Deformation in Hot Mix Asphalt. International Journal of Geomechanics, Vol. 7, No. 2, 2007, pp. 119-130.

22. Tashman, L., E. Masad, D. Little, and H. Zbib. A Microstructure-Based Viscoplastic Model for Asphalt Concrete. International Journal of Plasticity, Vol. 21, No. 9, 2005, pp. 16591685.

23. Tan, S.-A., B.-H. Low, and T.-F. Fwa. Behavior of Asphalt Concrete Mixtures in Triaxial Compression. Journal of Testing and Evaluation, Vol. 22, No. 3, 1994, pp. 195-203.

24. Abu Al-Rub, R.K., M.K. Darabi, C.-W. Huang, E.A. Masad, and D.N. Little. Comparing Finite Element and Constitutive Modelling Techniques for Predicting Rutting of Asphalt Pavements. International Journal of Pavement Engineering, Vol. 13, No. 4, 2012, pp. 322338.

25. Zhang, Y., Anisotropic Characterization of Asphalt Mixtures in Compression. Civil Engineering. Ph.D. Dissertation, Texas A\&M University, College Station, Texas, USA, 2012.

26. Oda, M. and H. Nakayama. Yield Function for Soil with Anisotropic Fabric. Journal of Engineering Mechanics, Vol. 115, No. 1, 1989, pp. 89-104.

27. Zhang, Y., R. Luo, and R.L. Lytton. Microstructure-Based Inherent Anisotropy of Asphalt Mixtures. Journal of Materials in Civil Engineering, Vol. 23, No. 10, 2011, pp. 1473-1482.

28. Lemaitre, J. and R. Desmorat, Engineering Damage Mechanics: Ductile, Creep, Fatigue and Brittle Failures. Springer, LLC, New York, NY, 2005.

29. Kachanov, L.M., Introduction to Continuum Damage Mechanics. Springer, LLC, New York, NY, 1986.

30. Chaboche, J.L. Continuum Damage Mechanics: Present State and Future Trends. Nuclear Engineering and Design, Vol. 105, No. 1, 1987, pp. 19-33.

31. Zhang, Y., R. Luo, and R.L. Lytton. Characterizing Permanent Deformation and Fracture of Asphalt Mixtures by Using Compressive Dynamic Modulus Tests. Journal of Materials in Civil Engineering, Vol. 24, No. 7, 2012, pp. 898-906.

32. Luo, X., Y. Zhang, and R.L. Lytton. Implementation of Pseudo J-Integral Based Paris' Law for Fatigue Cracking in Asphalt Mixtures and Pavements. Materials and Structures, Vol. 49, No. 9, 2016, pp. 3713-3732.

33. Luo, X., R. Luo, and R.L. Lytton. Modified Paris's Law to Predict Entire Crack Growth in Asphalt Mixtures. In Transportation Research Record: Journal of the Transportation 
Research Board, No. 2373, Transportation Research Board of the National Academies, Washington, D.C., 2013, pp. 54-62.

34. Gu, F., X. Luo, Y. Zhang, and R.L. Lytton. Using Overlay Test to Evaluate Fracture Properties of Field-Aged Asphalt Concrete. Construction and Building Materials, Vol. 101, No. 1, 2015, pp. 1059-1068.

35. Gu, F., Y. Zhang, X. Luo, R. Luo, and R.L. Lytton. Improved Methodology to Evaluate Fracture Properties of Warm-Mix Asphalt Using Overlay Test. In Transportation Research Record: Journal of the Transportation Research Board, No. 2506, Transportation Research Board of the National Academies, Washington, D.C., 2015, pp. 8-18.

36. Yi, J., S. Shen, B. Muhunthan, and D. Feng. Viscoelastic-Plastic Damage Model for Porous Asphalt Mixtures: Application to Uniaxial Compression and Freeze-Thaw Damage. Mechanics of Materials, Vol. 70, No. 2014, pp. 67-75.

37. Zhang, Y., R. Luo, and R.L. Lytton. Characterization of Viscoplastic Yielding of Asphalt Concrete. Construction and Building Materials, Vol. 47, No. 2013, pp. 671-679. 


\section{LIST OF TABLES}

TABLE 1 Testing Methods, Asphalt Mixture Types, Material Properties Determined as Model Inputs and Data Resources

\section{LIST OF FIGURES}

FIGURE 1 Stress-strain curves of an asphalt mixture lab test results vs. viscoelastic (VE), viscoelastic-plastic (VEP), and viscoelastic-plastic-fracture (VEPF) model predictions (including damage density and effective viscoplastic strain predicted by VEPF model).

FIGURE 2 Stress-strain curves of laboratory compressive strength test results and viscoelastic-plastic-fracture (VEPF) model predictions for the four different asphalt mixtures.

FIGURE 3. Stress-strain curves of compressive strength test results and viscoelasticplastic-fracture (VEPF) model prediction for an asphalt mixture (N4-0) at three different confining pressures.

FIGURE 4. Stress-strain curves of compressive strength test results and viscoelasticplastic-fracture (VEPF) model predictions for an asphalt mixture (N4-6) at five temperatures.

FIGURE 5 Total strain, viscoelastic (VE) and viscoplastic (VP) strain responses of viscoelastic-plastic-fracture (VEPF) models in a repeated load without rest periods.

FIGURE 6 Total strain, viscoelastic (VE) and viscoplastic (VP) strain responses of viscoelastic-plastic-fracture (VEPF) models in a cyclic load with rest periods. 
TABLE 1 Testing Methods, Asphalt Mixture Types, Material Properties Determined as Model Inputs and Data Resources

\begin{tabular}{|c|c|c|c|c|c|c|c|}
\hline \multirow{4}{*}{$\begin{array}{l}\text { Material } \\
\text { Property }\end{array}$} & \multirow{4}{*}{$\begin{array}{c}\text { Asphalt } \\
\text { Mixtures } \\
\text { Test Methods }\end{array}$} & \multirow{4}{*}{\begin{tabular}{|l|} 
Binder \\
Air Void \\
Aging \\
Label \\
\end{tabular}} & \multicolumn{4}{|c|}{ Binder-N (PG64-16) } & \multirow{4}{*}{$\begin{array}{c}\text { Data } \\
\text { Resources }\end{array}$} \\
\hline & & & \multicolumn{3}{|c|}{$4 \%$} & \multirow{2}{*}{\begin{tabular}{|c|}
$7 \%$ \\
$\begin{array}{c}6-\text {-month } \\
\text { aged }\end{array}$ \\
\end{tabular}} & \\
\hline & & & Unaged & $\begin{array}{c}\text { 3-month } \\
\text { aged }\end{array}$ & $\begin{array}{c}\text { 6-month } \\
\text { aged }\end{array}$ & & \\
\hline & & & N4-0 & N4-3 & N4-6 & N7-6 & \\
\hline \multirow{2}{*}{$\begin{array}{c}\text { Visco- } \\
\text { elasticity }\end{array}$} & \multirow{2}{*}{$\begin{array}{c}\text { Dynamic modulus } \\
\text { tests }(@ 10,25, \\
\left.40,55^{\circ} \mathrm{C}\right)\end{array}$} & $\begin{array}{l}K_{\infty}, K_{m} \\
G_{\infty}, G_{m} \\
\end{array}$ & \multicolumn{4}{|c|}{$\begin{array}{c}K(t) \text {, and } G(t) \text { are calculated from } E(t) \text { and } v_{0} \\
\text { at a reference temperature of } 40^{\circ} \mathrm{C} .\end{array}$} & $\begin{array}{l}\text { Table } 3 \text { of } \\
\text { Ref.(17). }\end{array}$ \\
\hline & & $\begin{array}{l}\Delta E \\
(J / m o l)\end{array}$ & 226,326 & 186,777 & 105,524 & 213,773 & $\begin{array}{l}\text { Table } 2 \text { of } \\
\text { Ref.(17) }\end{array}$ \\
\hline Anisotropy & $\Delta^{\prime}$ tests & $\Delta^{\prime}$ & 0.3106 & 0.3354 & 0.3880 & 0.4088 & $\begin{array}{r}\text { Table 8-2 } \\
\text { of Ref.(25) }\end{array}$ \\
\hline \multirow{14}{*}{$\begin{array}{c}\text { Visco- } \\
\text { plasticity }\end{array}$} & \multirow{7}{*}{$\begin{array}{c}* \text { Compressive } \\
\text { Strength }(\mathrm{CS}) \\
\text { tests } @ 40^{\circ} \mathrm{C} \text {, and } \\
\text { confinements of } \\
0,103.5,207 \mathrm{kPa}\end{array}$} & $\phi\left(^{\circ}\right)$ & 46.8 & 48.9 & 45.9 & 44.8 & \multirow{11}{*}{$\begin{array}{l}\text { Table } 3 \text { of } \\
\text { Ref.(37) }\end{array}$} \\
\hline & & $C(\mathrm{kPa})$ & 143.6 & 227.3 & 302.5 & 203.9 & \\
\hline & & $\alpha$ & 0.370 & 0.382 & 0.363 & 0.354 & \\
\hline & & $\kappa_{0}(k P a)$ & 150.8 & 241.5 & 319.6 & 218.4 & \\
\hline & & $\kappa_{l}(k P a)$ & 75.0 & 111.0 & 148.6 & 107.8 & \\
\hline & & $\kappa_{2}(1 / \varepsilon)$ & 3,060 & 11,010 & 6,410 & 4,430 & \\
\hline & & $d$ & 0.609 & 0.598 & 0.614 & 0.629 & \\
\hline & \begin{tabular}{|l|}
${ }^{\circledR} \mathrm{CS}$ tests on $\mathrm{N} 4-6$ \\
$@ 40,45,50,55,60^{\circ} \mathrm{C}$ \\
\end{tabular} & $\begin{array}{l}\Delta E_{k} \\
(J / m o l)\end{array}$ & NA & $\mathrm{NA}$ & 21,020 & NA & \\
\hline & \multirow{3}{*}{$\begin{array}{l}\text { CS tests on N7-6 } \\
\text { @ } 5 \text { strain rates }\end{array}$} & $a_{\min }$ & $\mathrm{NA}$ & NA & NA & 0.49 & \\
\hline & & $a_{\max }$ & NA & NA & NA & 1.91 & \\
\hline & & $\kappa_{3}$ & NA & NA & NA & 0.3811 & \\
\hline & Eq.19 & $\beta$ & 0.171 & 0.185 & 0.216 & 0.229 & \multirow{3}{*}{$\begin{array}{l}\text { Table 8-3 } \\
\text { of Ref.(25) }\end{array}$} \\
\hline & \multirow{2}{*}{$\begin{array}{c}\text { Repeated load tests } \\
\text { @ } 600 \mathrm{kPa}, 1 \mathrm{~Hz}\end{array}$} & $\Gamma(1 / s)$ & \begin{tabular}{|l|}
$1.30 \mathrm{E}-7$ \\
\end{tabular} & $9.12 \mathrm{E}-8$ & $2.31 \mathrm{E}-8$ & \begin{tabular}{|l|}
$8.90 \mathrm{E}-8$ \\
\end{tabular} & \\
\hline & & $N$ & 1.71 & 1.71 & 1.77 & 1.90 & \\
\hline \multirow{5}{*}{$\begin{array}{l}\text { Visco- } \\
\text { fracture }\end{array}$} & Eq. 24 & $c(\mathrm{~mm})$ & 0.65 & 0.65 & 0.65 & 0.79 & \multirow{3}{*}{$\begin{array}{l}\text { Fig.5 of } \\
\text { Ref.(4) }\end{array}$} \\
\hline & $\begin{array}{l}{ }^{\&} \mathrm{CS} \text { tests on } \mathrm{N} 4-6 \\
@ 40,45,50,55,60^{\circ} \mathrm{C} \\
\end{array}$ & $\Delta E_{G}(J / m o l)$ & NA & NA & 36,016 & NA & \\
\hline & ${ }^{*} \mathrm{CS}$ tests at $40^{\circ} \mathrm{C}$ & $\Delta G(N / \mathrm{m})$ & \begin{tabular}{|l|}
0.079 \\
\end{tabular} & 0.155 & 0.324 & 0.224 & \\
\hline & and confinements & $A(1 / s)$ & \begin{tabular}{|l|}
$2.39 \mathrm{E}-6$ \\
\end{tabular} & $1.01 \mathrm{E}-7$ & $3.00 \mathrm{E}-9$ & \begin{tabular}{|l|}
$4.50 \mathrm{E}-8$ \\
\end{tabular} & \multirow{2}{*}{$\begin{array}{l}\text { Fig. } 4 \text { of } \\
\text { Ref.(5) }\end{array}$} \\
\hline & $\begin{array}{c}\text { of } 0,103.5,207 \\
\mathrm{kPa}\end{array}$ & $n$ & 1.404 & 1.720 & 2.099 & 1.715 & \\
\hline
\end{tabular}




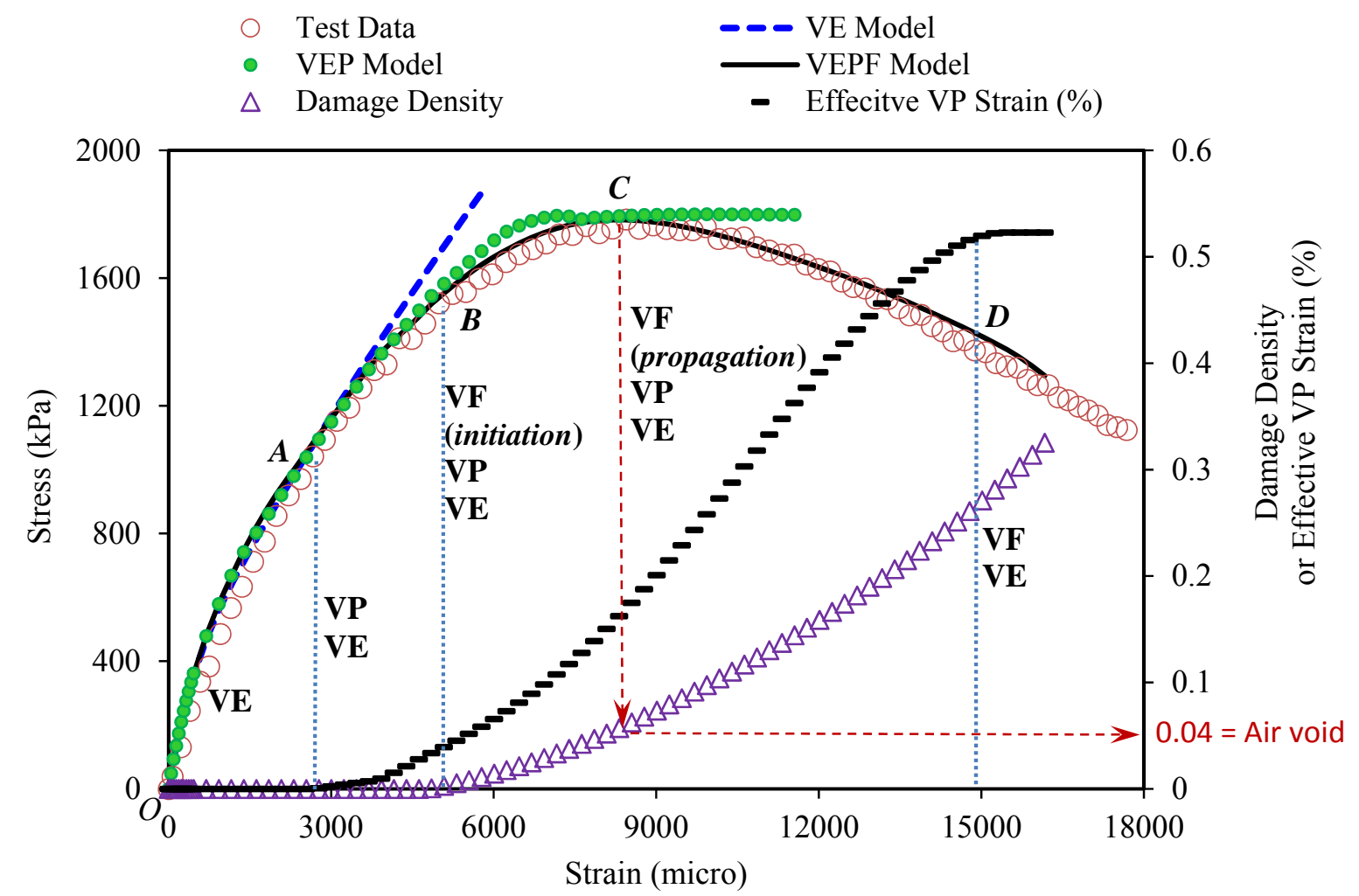

FIGURE 1 Stress-strain curves of an asphalt mixture lab test results vs. viscoelastic (VE), viscoelastic-plastic (VEP), and viscoelastic-plastic-fracture (VEPF) model predictions (including damage density and effective viscoplastic strain predicted by VEPF model). 


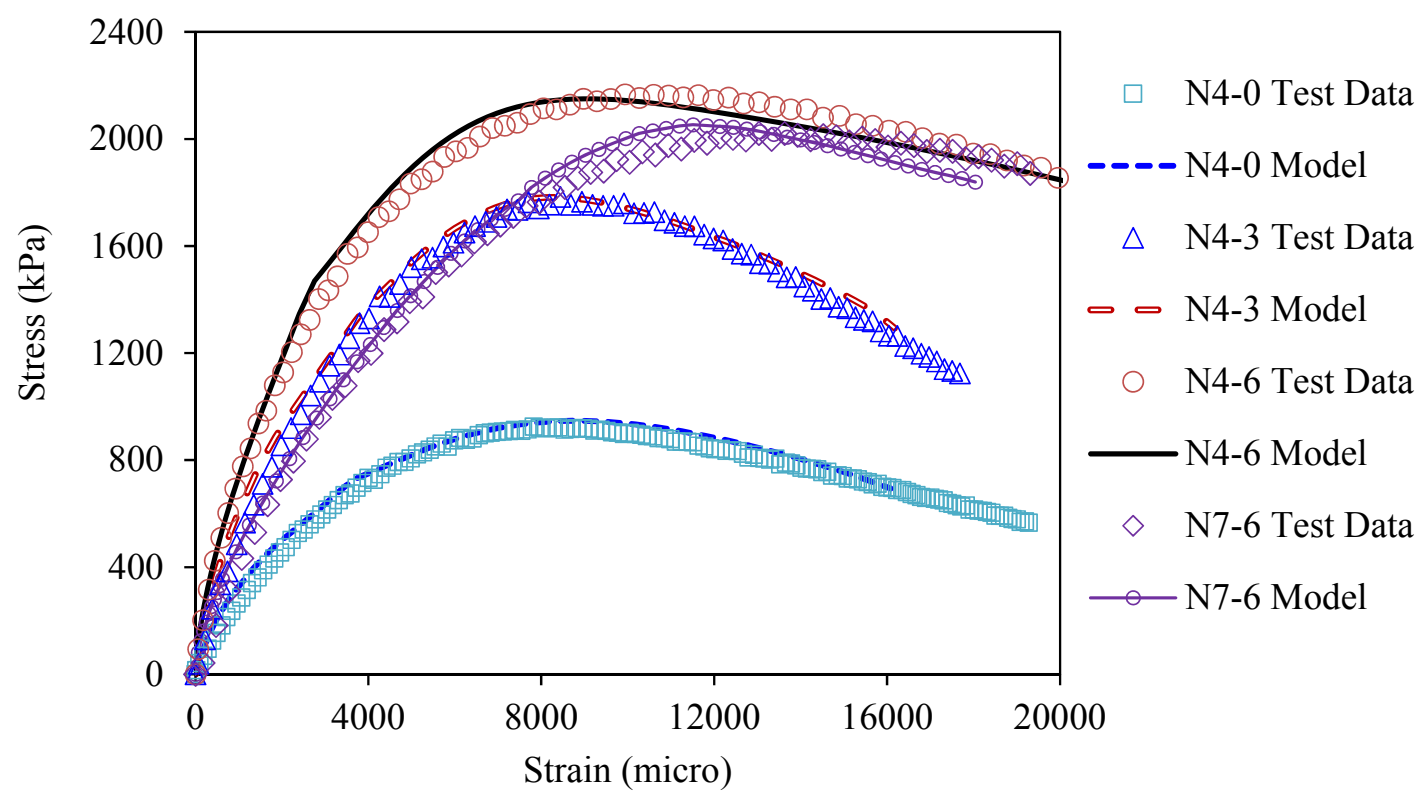

FIGURE 2 Stress-strain curves of laboratory compressive strength test results and viscoelastic-plastic-fracture (VEPF) model predictions for the four different asphalt mixtures. 


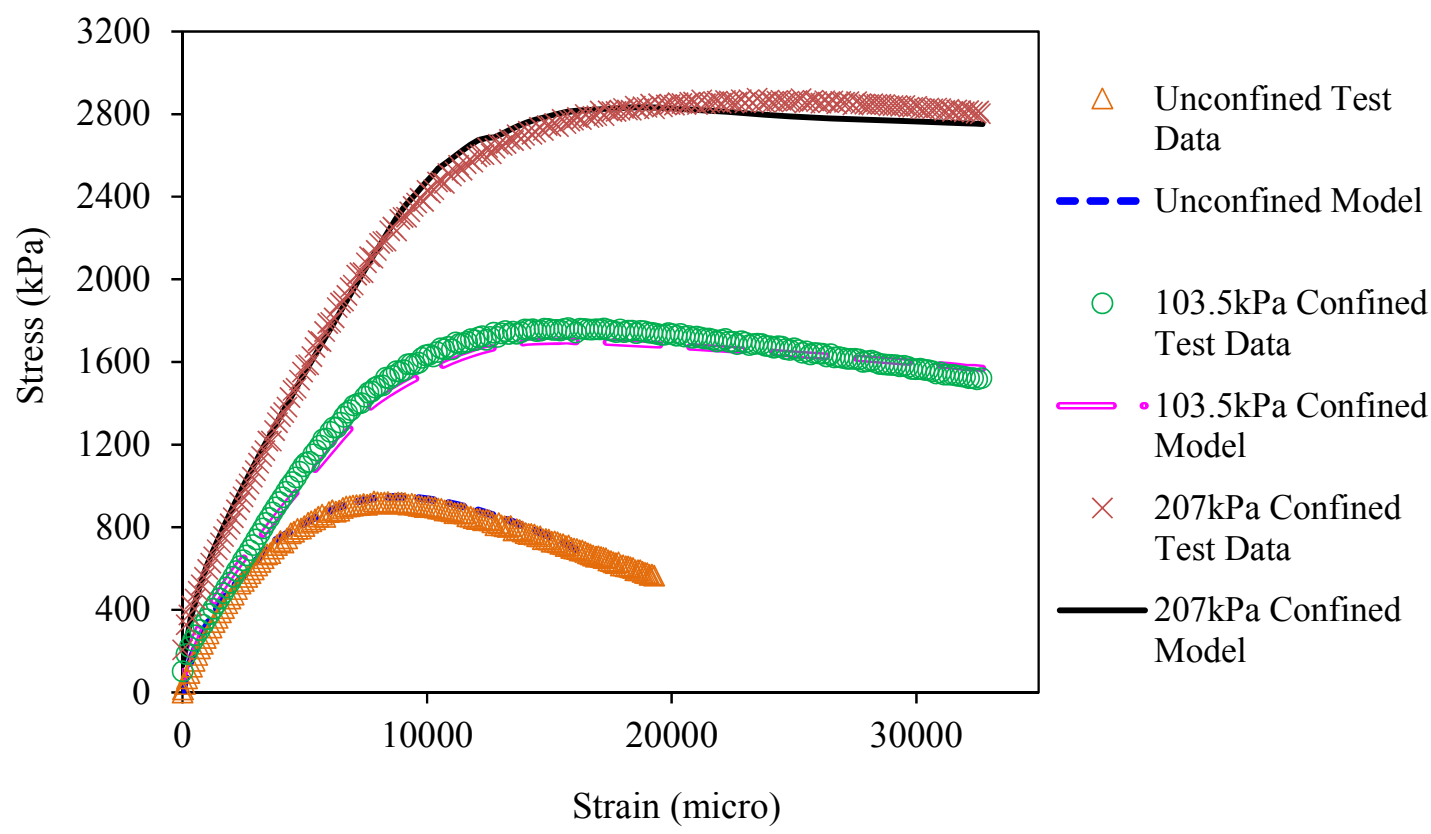

FIGURE 3. Stress-strain curves of compressive strength test results and viscoelasticplastic-fracture (VEPF) model prediction for an asphalt mixture (N4-0) at three different confining pressures. 


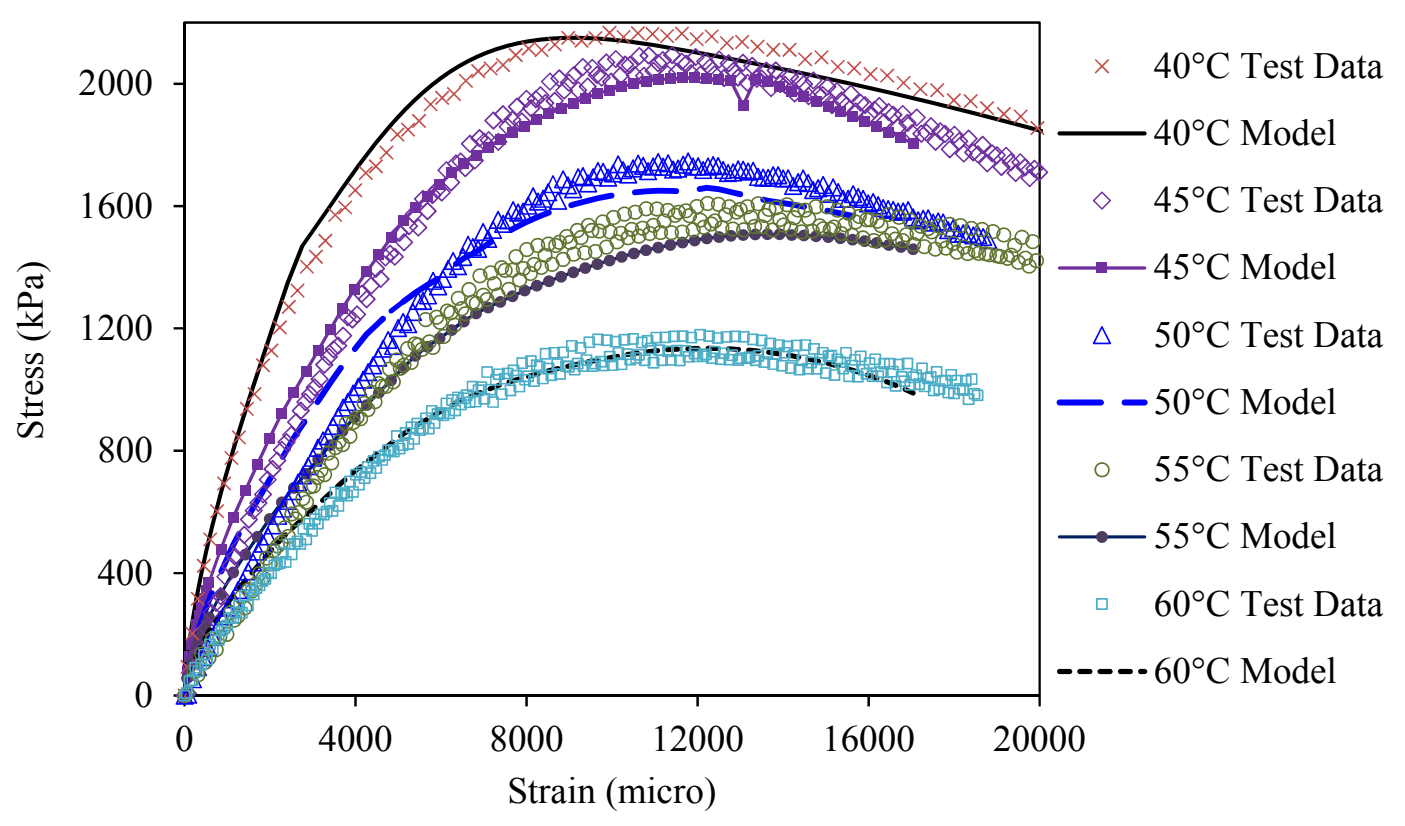

FIGURE 4. Stress-strain curves of compressive strength test results and viscoelasticplastic-fracture (VEPF) model predictions for an asphalt mixture (N4-6) at five temperatures. 


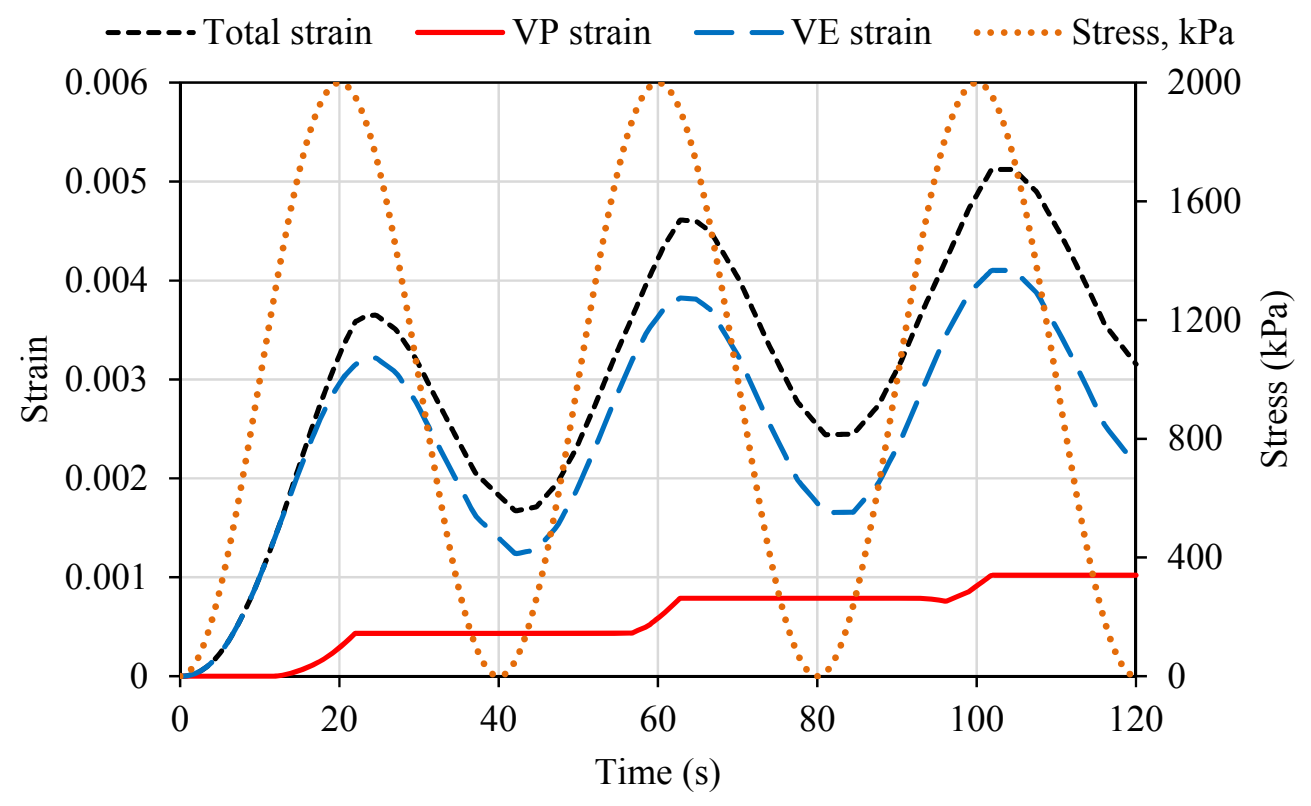

FIGURE 5 Total strain, viscoelastic (VE) and viscoplastic (VP) strain responses of viscoelastic-plastic-fracture (VEPF) models in a repeated load without rest periods. 


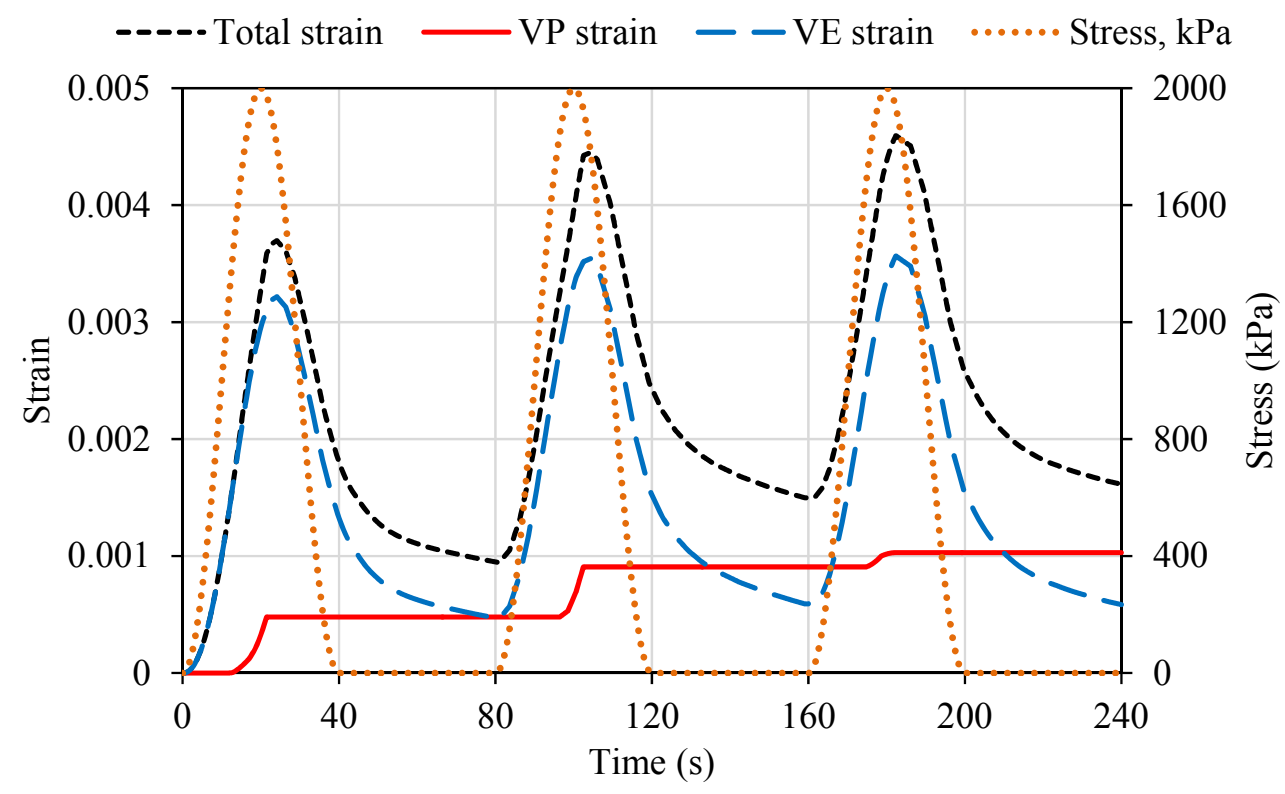

FIGURE 6 Total strain, viscoelastic (VE) and viscoplastic (VP) strain responses of viscoelastic-plastic-fracture (VEPF) models in a cyclic load with rest periods. 